\title{
Synthesis and anticancer activity evaluation of some acridine derivatives
}

\author{
Surbhi Arya $\cdot$ Anuj Kumar $\cdot$ Nikhil Kumar • \\ Partha Roy $\cdot$ S. M. Sondhi
}

Received: 12 June 2014/ Accepted: 17 September 2014/Published online: 26 September 2014

(C) Springer Science+Business Media New York 2014

\begin{abstract}
Amino acridine derivatives (1a-1h) on condensation with 9,10 -dihydroanthracene- $9,10-\alpha, \beta$-succinic anhydride (2) at room temperature gave condensation products (3a-3h). Microwave-assisted condensation of 9-amino acridine derivatives (1a-1d) with phthalic anhydride, cis 1,2,3,6-tetrahydrophthalimide, and 2,5-pyrroledione gave corresponding condensation products $4 \mathbf{a}-\mathbf{4 d}, \mathbf{5 a}-\mathbf{5 d}$ \& 6a-6d, respectively, in good yields. All these compounds were screened for in vitro anticancer activity against five human cancer cell lines i.e., breast (T47D), lung (NCl H-522), colon (HCT-15), ovary (PA-1), and liver (Hep G2). Compounds 3a (breast T47D), $3 \mathbf{g}$ (lung $\mathrm{NCl}$ H-522), 4a (liver Hep G2), and 6b (colon HCT-15) exhibited $\mathrm{IC}_{50}$ values $5.4,4.2,4.5$, and $2.4 \mu \mathrm{M}$, respectively, and hence possess good anticancer activity.
\end{abstract}

Keywords Synthesis - Acridine derivatives .

Human cancer cell lines · Anticancer

\section{Introduction}

Acridine derivatives form an important class of heterocyclic compounds due to their broad range of pharmaceutical properties. Acridine derivatives exhibiting anti-inflammatory (Chen et al., 2002; Yartseva et al., 2003), anticancer (El-Deiry, 2008; Maurice et al., 2009), antimicrobial (Ali

S. Arya $\cdot$ A. Kumar $\cdot$ S. M. Sondhi $(\bowtie)$

Department of Chemistry, Indian Institute of Technology-

Roorkee, Roorkee 247667, UK, India

e-mail: sondifcy@iitr.ernet.in

N. Kumar · P. Roy

Department of Biotechnology, Indian Institute of Technology-

Roorkee, Roorkee 247667, UK, India and El-Kazak, 2010; Prabakaran et al., 2011), antitubercular (Aly and Abadi, 2004; Tripathi et al., 2006), anti-HIV (Aly et al., 1997), anti herpes (Goodell et al., 2006), antiparasitic (Di Giorgio et al., 2005), antimalarial (Kumar et al., 2009; Tomer et al., 2010; Yu et al., 2012), antiviral (Gupta and Jaiswal, 2010; Tonelli et al., 2011), and fungicidal (Srivastava and Nizamuddin, 2004) activities are well documented in the literature. Acridine derivatives are also reported to be useful in the treatment of Alzheimer's and Parkinson's disease (Lp et al., 2008; Wurster et al., 2001) and chronic pulmonary disease (Gopalan et al., 2006). In continuation of our efforts (Sondhi et al., 2010; 2013) in search of potent molecules possessing anticancer activity, we have synthesized a number of acridine derivatives and screened them for anticancer activity which we wish to report in this paper.

\section{Results and discussion}

Chemistry

9-Amino-3-methylacridine (1a; Scheme 1), 9-amino-2methylacridine (1b), 9-amino-4-methoxyacridine (1c), 9-amino-4-ethoxyacridine (1d), 9-amino-4-methylacridine (1e), 9-amino-3-methoxyacridine (1f), 9-amino-2-methoxyacridine (1g), and 9-aminoacridine (1h) were synthesized by condensation of corresponding $N$-arylanthranilic acid (Allen and Mckee, 1959) with phosphorus oxychloride and subsequent conversion of 9-chloroacridines to 9-aminoacridines by following reaction procedure reported in the literature (Albert and Gledhill, 1945; Albert and Ritchie, 1960). 9, 10-dihydroanthracene- $9,10-\alpha$, and $\beta$-succinic anhydride (2; Scheme 1) were synthesized by following reaction procedure reported in the literature (Vogel, 1968). 
9-Amino-3-methylacridine (1a; Scheme 1) and 9, 10-dihydroanthracene-9, 10- $\alpha, \beta$-succinic anhydride were taken in equimolar ratio and dissolved separately in minimum amount of dry tetrahydrofuran (THF). These two solutions were mixed together and allowed to stand at room temperature for $20 \mathrm{~h}$. Solvent was removed under reduced pressure and crude product so obtained was washed with chilled THF and then crystallized from methanol to give pure yellow product $N$-(3-methylacridin-9-yl)-9,10-dihydro9,10-ethanoanthracene-11, 12-dicarbiximide (3a; Scheme 1) in $89 \%$ yield. IR spectrum of 3a shows absorption bands at $1691(\mathrm{C}=\mathrm{O}), 1657(\mathrm{C}=\mathrm{N})$, and 1586 and $1493(\mathrm{C}=\mathrm{C}, \mathrm{Ar})$ $\mathrm{cm}^{-1}$. ${ }^{1} \mathrm{H}$ NMR (500 MHz, DMSO-d $) \delta: 2.93$ (s, 2H, $2 \times \mathrm{CH}), 2.97\left(\mathrm{~s}, 3 \mathrm{H}, \mathrm{CH}_{3}\right), 4.65(\mathrm{~s}, 2 \mathrm{H}, 2 \times \mathrm{CH}), 7.15(\mathrm{~s}$, $1 \mathrm{H}, \quad \mathrm{Ar}-\mathrm{H}), \quad 7.04-8.45$ (m, 14H, Ar-H). ${ }^{13} \mathrm{C} \mathrm{NMR}$ $\left(125 \mathrm{MHz}\right.$, DMSO- $\left.d_{6}\right) \delta: 18.15,46.64,48.79,112.38$, $112.49,121.82,122.28,122.69,123.84,123.80,124.89$, $125.20,125.64,132.25,135.04,141.46,143.65,148.49$, 154.99 173.44. APCI-MS: m/z $467.6\left(\mathrm{M}^{+}+\mathrm{H}, 100 \%\right)$. Elemental Anal. Calcd. for $\mathrm{C}_{32} \mathrm{H}_{22} \mathrm{~N}_{2} \mathrm{O}_{2} \mathrm{C} 82.40, \mathrm{H} 4.72, \mathrm{~N}$ 6.00 ; Found $\mathrm{C} 82.43, \mathrm{H} 4.75, \mathrm{~N} 6.00 \%$. Spectral and analytical data of 3a fully support the structure assigned to it.

Similarly condensation of 9-amino-2-methylacridine (1b), 9-amino-4-methoxyacridine (1c), 9-amino-4-ethoxyacridine (1d), 9-amino-4-methylacridine (1e), 9-amino-3- methoxyacridine (1f), 9-amino-2-methoxyacridine (1g), and 9-amino acridine (1h) with 9, 10-dihydroanthracene-9, 10 - $\alpha, \beta$-succinic anhydride (2) gave corresponding condensation products $\mathbf{3 b}-\mathbf{3 h}$ (Scheme 1). All the condensation products were purified by crystallization and structures assigned to $\mathbf{3 a} \mathbf{-} \mathbf{3 h}$ are fully supported by spectral data i.e., IR, ${ }^{1} \mathrm{H}$ NMR, ${ }^{13} \mathrm{C}$ NMR, GC-MS, LC-MS, and elemental analysis reported in experimental section of this paper.

Condensation of 9-amino-3-methylacridine (1a) with phthalic anhydride (Scheme 1) was carried out by mixing both the reactants in equimolar ratio and then irradiating the reaction mixture in a microwave reactor at $120^{\circ} \mathrm{C}$ for 5 min. TLC of reaction mixture over silica gel using $\mathrm{CHCl}_{3}: \mathrm{MeOH}(8.5: 1.5)$ as mobile phase shows the presence of starting materials. Reaction mixture was again irradiated at $120{ }^{\circ} \mathrm{C}$ for $5 \mathrm{~min}$. TLC of reaction mixture showed the absence of starting materials and the presence of a new compound. The crude product so obtained was purified by crystallization from methanol to give pure yellow product 2-(3-methylacridin-9-yl) isoindoline-1,3dione (4a) in $93 \%$ yield.

Alternatively, both the reactants were mixed in equimolar ratio and then irradiated in a domestic microwave oven at a power level of 600 Watt for $5 \mathrm{~min}$. TLC of reaction mixture over silica gel using $\mathrm{CHCl}_{3}: \mathrm{MeOH}$ (8.5:1.5) as mobile phase shows the presence of starting
Scheme 1 Synthesis of acridine derivatives

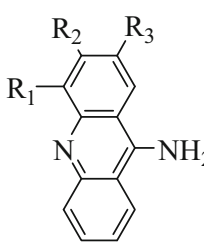

1a-h<smiles>[R]c1cc2c(N3C(=O)c4ccccc4C3=O)c3ccccc3nc2c([R])c1[R]</smiles>
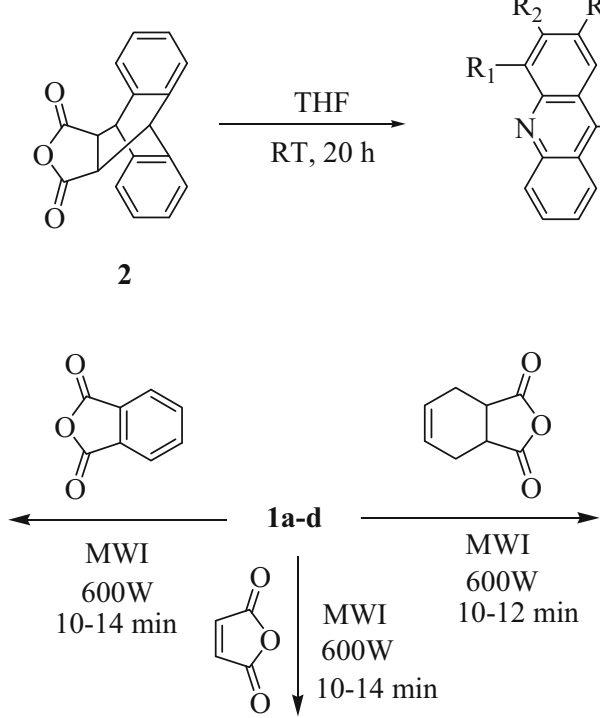<smiles>[R]c1cc2c(N3C(=O)C=CC3=O)c3ccccc3nc2c([R])c1[R]</smiles>

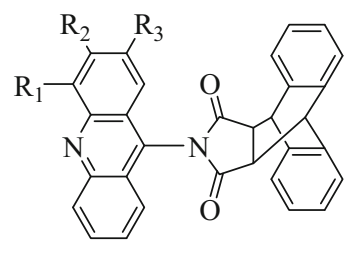

3a-h<smiles>[R3]c1cc2c(N3C(=O)C4CC=CCC4C3=O)c3ccccc3nc2c([R])c1[R]</smiles>

6a-d 
materials. This reaction mixture was again irradiated for $5 \mathrm{~min}$ and TLC of reaction mixture showed the absence of starting materials and formation of new product. This crude product was crystallized from methanol to give the pure product $\mathbf{4 a}$ in $92 \%$ yield.

Reaction products obtained from both the methods were found to be same as monitored by TLC and co-TLC. Both the methods gave quantitative yield of condensed product. IR spectrum of $4 \mathbf{a}$ shows absorption bands at $1653(\mathrm{C}=\mathrm{O})$, $1588,1549 \& 1481(\mathrm{C}=\mathrm{C}, \mathrm{Ar}) \mathrm{cm}^{-1} .{ }^{1} \mathrm{H}$ NMR $(500 \mathrm{MH} z$, DMSO- $\left.d_{6}\right) \delta: 2.99\left(\mathrm{~s}, 3 \mathrm{H}, \mathrm{CH}_{3}\right), 7.33-8.59(\mathrm{~m}, 11 \mathrm{H}$, Ar-H). ${ }^{13} \mathrm{C}$ NMR (125 MHz, DMSO- $\left.d_{6}\right) \delta: 23.66,111.95$, $113.26,117.14,118.68,124.20,124.89,127.30,128.60$, 130.97, 132.89, 135.18, 135.74, 137.89, 138.98, 141.63, 159.73, 168.83, APCI-MS: m/z $339.1\left(\mathrm{M}^{+}+\mathrm{H}, 100 \%\right)$. Elemental Anal. Calcd. for $\mathrm{C}_{22} \mathrm{H}_{14} \mathrm{~N}_{2} \mathrm{O}_{2}: \mathrm{C} 78.10, \mathrm{H} 4.14$, N 8.28; Found C 78.19, H 4.21, N 8.38\%. Spectral and analytical data of $\mathbf{4 a}$ are in full agreement with the structure assigned to it.

Similarly, condensation of 9-amino-3-methylacridine (1a), 9-amino-2-methylacridine (1b), 9-amino-4-methoxyacridine (1c), and 9-amino-4-ethoxyacridine (1d) with phthalic anhydride, cis-1,2,3,6-tetrahydrophthalimide, and 2,5-pyrroledione gave corresponding condensation products 4a-4d, 5a-5d, and 6a-6d, respectively, (Scheme 1). All these compounds were purified by crystallization. Spectral (IR, ${ }^{1} \mathrm{H}$ NMR, ${ }^{13} \mathrm{C}$ NMR, GC-MS \& LC-MS) data and elemental analysis of $4 \mathbf{a}-\mathbf{4 d}, \mathbf{5 a}-\mathbf{5 d}$, and $\mathbf{6 a}-\mathbf{6 d}$ (Scheme 1) reported in experimental section of this paper are in agreement with structures assigned to them.

Compounds 3a-3h, 4a-4d, 5a-5d, and 6a-6d were screened for in vitro anticancer activity (Mosmann, 1983) against five human cancer cell lines i.e., breast (T47D), lung (NCl H-522) colon (HCT-15), ovary (PA-1), and liver (Hep G2) at a concentration of $1 \times 10^{-5} \mathrm{M}$ and results are summarized in Table 1. A look at Table 1 indicates that compounds 3a, 3d, 4b, 4d, 5a, 5b, $\mathbf{6 b}$ (breast T47D); 3a, 3g, 4b, 5b, 6b (lung NCl H-522); 3a, 3g, 4a, 4b, 4d, 5a, 5b, 6b (colon HCT-15); 3d, 4a, 4b (ovary PA-1); and 3a, 3g, 4a, 4b, 4d, 5a, 5b, 6b (liver Hep G2) exhibited good anticancer activity against various cancer cell lines mentioned above. Compounds 3a, 3d, 3g, 4a, 4b, 4d, 5a, 5b, and $\mathbf{6 b}$ which showed good anticancer activity were further studied and their $\mathrm{IC}_{50}$ values for various cancer cell lines and normal cell line (COS-1) are determined and reported in Table 2. Compounds $\mathbf{4 b}$ and $\mathbf{3 a}, \mathbf{5 b}, \mathbf{6 b}$ showed good anticancer activity against five and four cancer cell lines, respectively. Compounds 3a (breast T47D), 3g (lung NCl H-522), 4a (liver Hep G2), and 6b (colon HCT-15) exhibited $\mathrm{IC}_{50}$ values $5.4,4.2,4.5$, and $2.4 \mu \mathrm{M}$, respectively, and hence possess good anticancer activity.
Table 1 In vitro anticancer activity of acridine derivatives $\mathbf{3 a}-\mathbf{3 h}$, 4a-4d, 5a-5d \& 6a-6d

\begin{tabular}{|c|c|c|c|c|c|}
\hline \multirow[t]{2}{*}{ Compd. no. } & \multicolumn{5}{|c|}{$\begin{array}{l}{ }^{a} \text { Anticancer activity (\% growth inhibition) at a } \\
\text { concentration of } 1 \times 10^{-5} \mathrm{M}\end{array}$} \\
\hline & $\begin{array}{l}\text { Breast } \\
\text { T47D }\end{array}$ & $\begin{array}{l}\text { Lung } \\
\text { NCI H-522 }\end{array}$ & $\begin{array}{l}\text { Colon } \\
\text { HCT-15 }\end{array}$ & $\begin{array}{l}\text { Ovary } \\
\text { PA-1 }\end{array}$ & $\begin{array}{l}\text { Liver } \\
\text { HepG2 }\end{array}$ \\
\hline $\mathbf{3 a}$ & 67 & 70 & 70 & 67 & 72 \\
\hline 3b & 62 & 54 & 50 & 67 & 54 \\
\hline $3 c$ & 61 & 60 & 64 & 69 & 68 \\
\hline 3d & 65 & 54 & 57 & 70 & 70 \\
\hline $3 e$ & 58 & 50 & 54 & 68 & 70 \\
\hline $3 f$ & 41 & 50 & 32 & 65 & 50 \\
\hline $3 g$ & 64 & 73 & 69 & 68 & 71 \\
\hline $3 \mathbf{h}$ & 37 & 34 & 35 & 56 & 46 \\
\hline $4 \mathbf{a}$ & 61 & 65 & 74 & 70 & 74 \\
\hline $4 b$ & 66 & 71 & 74 & 70 & 76 \\
\hline $4 c$ & 53 & 58 & 44 & 68 & 55 \\
\hline $4 d$ & 65 & 60 & 69 & 66 & 71 \\
\hline $5 a$ & 68 & 65 & 73 & 67 & 73 \\
\hline $5 b$ & 65 & 70 & 72 & 65 & 72 \\
\hline $5 c$ & 58 & 60 & 65 & 67 & 63 \\
\hline $5 d$ & 64 & 60 & 68 & 68 & 66 \\
\hline $6 a$ & 57 & 60 & 62 & 66 & 70 \\
\hline 6b & 65 & 71 & 70 & 66 & 73 \\
\hline $6 c$ & 07 & 11 & 17 & 03 & 26 \\
\hline 6d & 62 & 54 & 54 & 67 & 66 \\
\hline $5-\mathrm{FU}$ & 20 & 27 & 23 & 21 & 22 \\
\hline CYC-PHO & 27 & 17 & 17 & 35 & 29 \\
\hline CYC-HEXI & 18 & 20 & 17 & 35 & 18 \\
\hline
\end{tabular}

Bold values represent compounds showing good anticancer activity 5-FU 5-fluorouracil, CYC-PHO cyclophosphamide, CYC-HEXI cycloheximide

${ }^{\text {a }}$ Compounds tested in triplicate, data expressed as mean value of three independent experiments

Structure-activity relationship

Four series of acridine derivatives i.e., $\mathbf{3 a}-\mathbf{3 h}, \mathbf{4 a}-\mathbf{4 d}, \mathbf{5 a}-$ 5d, and 6a-6d are screened for in vitro anticancer activity against five human cancer cell lines i.e., breast (T47D), lung ( $\mathrm{NCl} \mathrm{H-522),} \mathrm{colon} \mathrm{(HCT-15),} \mathrm{ovary} \mathrm{(PA-1),} \mathrm{and}$ liver (Hep G2). Compounds 3a, 3g, 4a, and $\mathbf{6 b}$ exhibited good anticancer activity with $\mathrm{IC}_{50}$ values $5.4,4.2,4.5$, and $2.4 \mu \mathrm{M}$. A look at structures of these molecules shows that substitution at position 7 or 8 of acridine moiety with electron-donating group makes these molecules more active. This may be due to effective interaction of these molecules with the DNA as compared to other derivatives. 
Table $2 \mathrm{IC}_{50}$ values of in vitro anticancer activity of active compounds

\begin{tabular}{|c|c|c|c|c|c|c|}
\hline \multirow[t]{2}{*}{ Compd. no. } & \multicolumn{6}{|l|}{$\mathrm{IC}_{50}(\mu \mathrm{M})$} \\
\hline & $\begin{array}{l}\text { Breast } \\
\text { T47D }\end{array}$ & $\begin{array}{l}\text { Lung } \\
\text { NCI-H522 }\end{array}$ & $\begin{array}{l}\text { Colon } \\
\text { HCT-15 }\end{array}$ & $\begin{array}{l}\text { Ovary } \\
\text { PA-1 }\end{array}$ & $\begin{array}{l}\text { Liver } \\
\text { HepG2 }\end{array}$ & $\begin{array}{l}\text { Normal cell } \\
\text { COS- } 1\end{array}$ \\
\hline $3 \mathbf{a}$ & $5.4 \pm 1.28$ & $4.78 \pm 3.7$ & $4.9 \pm 1.2$ & $8.56 \pm 1.18$ & $5 \pm 2.11$ & $28 \pm 4.2$ \\
\hline 3d & $7.89 \pm 3.01$ & $11.3 \pm 2.3$ & $10.12 \pm 1.2$ & $5.98 \pm 1.23$ & $5.7 \pm 1.11$ & $76.55 \pm 9.57$ \\
\hline $3 g$ & $7.9 \pm 1.11$ & $4.2 \pm 1.3$ & $7 \pm 2.1$ & $5.6 \pm 1.6$ & $5.3 \pm 1.4$ & $17.38 \pm 2.0$ \\
\hline $4 a$ & $9.2 \pm 1.16$ & $8.5 \pm 2.87$ & $4.98 \pm 1.11$ & $7.2 \pm 2.1$ & $4.5 \pm 1.6$ & $45.84 \pm 3.24$ \\
\hline $4 b$ & $8.23 \pm 3.10$ & $4.5 \pm 2.10$ & $5.76 \pm 1.23$ & $7.17 \pm 0.83$ & $4.73 \pm 1.13$ & $15.24 \pm 2.1$ \\
\hline $4 d$ & $8 \pm 2.91$ & $9.0 \pm 3.1$ & $6.2 \pm 1.09$ & $8.7 \pm 2.01$ & $5.2 \pm 1.32$ & $20.97 \pm 2.5$ \\
\hline $5 \mathbf{a}$ & $7.9 \pm 2.12$ & $8.64 \pm 2.8$ & $5.02 \pm 1$ & $8.5 \pm 3.01$ & $5.2 \pm 2.01$ & $7.2 \pm 1.3$ \\
\hline $5 b$ & $8.14 \pm 1.17$ & $5.65 \pm 2.0$ & $6.2 \pm 2.8$ & $7.11 \pm 1.33$ & $4.98 \pm 1.05$ & $8.4 \pm 1.11$ \\
\hline $6 b$ & $8.04 \pm 1.39$ & $4.6 \pm 1.06$ & $2.4 \pm 2.7$ & $7.89 \pm 2.8$ & $5.11 \pm 1.62$ & $17.18 \pm 1.94$ \\
\hline $5-\mathrm{FU}$ & $51.8 \pm 2.34$ & $53.76 \pm 3.4$ & $43.01 \pm 1.45$ & $36.5 \pm 3.32$ & $29.87 \pm 1.82$ & $110 \pm 8.98$ \\
\hline CYC-PHO & $70.1 \pm 2.32$ & $63.9 \pm 3.79$ & $72.32 \pm 4.68$ & $63.12 \pm 5.43$ & $51.3 \pm 3.59$ & $125.43 \pm 9.24$ \\
\hline CYC-HEXI & $65.13 \pm 7.31$ & $57.1 \pm 5.34$ & $51.13 \pm 3.65$ & $40.6 \pm 2.09$ & $57.12 \pm 4.65$ & $128.31 \pm 7.89$ \\
\hline
\end{tabular}

Bold values represent compounds showing good anticancer activity

$50 \%$ growth inhibition as determined by MTT assay ( $24 \mathrm{~h}$ drug exposure). Compounds tested in triplicate, data expressed as mean value \pm SD of three independent experiments

5-FU 5-fluorouracil, CYC-PHO cyclophosphamide, CYC-HEXI cycloheximide

\section{Conclusion}

A number of acridine derivatives $3 \mathbf{a}-\mathbf{3 h}, \mathbf{4 a}-\mathbf{4 d}, \mathbf{5 a}-\mathbf{5 d}$, and 6a-6d have been synthesized in high yields using environment friendly reaction conditions. In vitro screening for anticancer activity was carried out against five human cancer cell lines. Compounds $\mathbf{3 a}$ (breast T47D), 3g (lung NCl H-522), 4a (liver Hep G2), and $6 \mathbf{b}$ (colon HCT15) exhibited good anticancer activity.

\section{Experimental}

Microwave reactor Anton Paar (monowave 300) and microwave oven model M197DL (Samsung) were used for microwave irradiation. Melting points $(\mathrm{mp})$ were determined on a JSGW apparatus and are uncorrected. IR spectra were recorded using a Perkin Elmer 1600 FT spectrometer. ${ }^{1} \mathrm{H}$ and ${ }^{13} \mathrm{C}$ NMR spectra were recorded on a Bruker WH-500 spectrometer at a ca 5-15\% $(w / v)$ solution in deuterated solvent. APCI mass was recorded using Finnigan Mat LCQ Mass Spectrometer. GC-MS was recorded on Perkin Elmer Clarus 500 gas chromatograph, where built in MS detector was used. Elemental analysis was carried out on a Vario EL III elementor. Thin layer chromatography (TLC) was performed on silica gel $\mathrm{G}$ for TLC (Merck) and spots were visualized by iodine vapor or by irradiation with ultraviolet light $(254 \mathrm{~nm})$.
Synthesis of 9-amino acridine derivatives $\mathbf{1 a}-\mathbf{1 h}$

9-Amino acridine derivatives $\mathbf{1 a}-\mathbf{1 h}$ were synthesized by following reaction procedure reported in the literature (Albert and Gledhill, 1945; Albert and Ritchie, 1960; Allen and Mckee, 1959).

Synthesis of 9, 10-dihydroanthracene- $9,10-\alpha, \beta-$ succinic anhydride (2)

9, 10-Dihydroanthracene- $9,10-\alpha, \beta$-succinic anhydride (2) was synthesized by following reaction procedure reported in the literature (Vogel, 1968).

General procedure for synthesis of acridine derivatives (3a-3h)

Synthesis of N-(3-methylacridin-9-yl)-9,10-dihydro-9,10ethanoanthracene-11, 12-dicarboximide (3a)

9-Amino-3-methylacridine (1a; $208 \mathrm{mg} ; 1 \mathrm{mmol})$ was dissolved in dry THF $(\approx 30 \mathrm{ml}) .9,10$-dihydroanthracene$9,10-\alpha, \beta$-succinic anhydride $(2 ; 276 \mathrm{mg} ; 1 \mathrm{mmol})$ was dissolved in dry THF $(\approx 40 \mathrm{ml})$. Clear solution of both the reactants was mixed and kept at room temperature for about $20 \mathrm{~h}$. Solvent of reaction mixture was removed under reduced pressure and the solid residue left behind was washed with chilled THF and the crude product so obtained 
was crystallized from methanol to give pure product $\mathrm{N}$-(3methylacridin-9-yl)-9,10-dihydro-9,10-ethanoanthracene-11, 12-dicarbiximide 3a. Yield $410 \mathrm{mg}$ (89\%). Yellow solid, mp 236-239 ${ }^{\circ} \mathrm{C}$. IR (KBr) $v_{\max }: 1691(\mathrm{C}=\mathrm{O}), 1657(\mathrm{C}=\mathrm{N})$, 1586 and $1493(\mathrm{C}=\mathrm{C}, \mathrm{Ar}) \mathrm{cm}^{-1} .{ }^{1} \mathrm{H}$ NMR $(500 \mathrm{MHz}$, DMSO- $\left.d_{6}\right) \delta: 2.93(\mathrm{~s}, 2 \mathrm{H}, 2 \times \mathrm{CH}), 2.97\left(\mathrm{~s}, 3 \mathrm{H}, \mathrm{CH}_{3}\right)$, $4.65(\mathrm{~s}, 2 \mathrm{H}, 2 \times \mathrm{CH}), 7.15(\mathrm{~s}, 1 \mathrm{H}, \mathrm{Ar}-\mathrm{H}), 7.04-8.45(\mathrm{~m}$, $14 \mathrm{H}, \mathrm{Ar}-\mathrm{H}) .{ }^{13} \mathrm{C}$ NMR $\left(125 \mathrm{MHz}, \mathrm{DMSO}-d_{6}\right) \delta: 18.15$, $46.64,48.79,112.38,112.49,121.82,122.28,122.69$, $123.84,123.80,124.89,125.20,125.64,132.25,135.04$, 141.46, 143.65, 148.49, 154.99 173.44. APCI-MS: m/z

$467.6\left(\mathrm{M}^{+}+\mathrm{H}, 100 \%\right), 274.3$

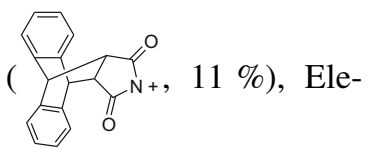

mental Anal. Calcd. for $\mathrm{C}_{32} \mathrm{H}_{22} \mathrm{~N}_{2} \mathrm{O}_{2} \mathrm{C} 82.40, \mathrm{H} 4.72, \mathrm{~N}$ 6.00; Found C 82.43, H 4.75, N $6.00 \%$.

Similarly, other acridine derivatives $\mathbf{3 b}-\mathbf{3 h}$ were synthesized. Physical constants and spectral data of $\mathbf{3 b} \mathbf{b} \mathbf{3 h}$ are summarized below.

$N$-(2-methylacridin-9-yl)-9,10-dihydro-9,10-

ethanoanthracene-11,12-dicarboximide (3b)

Solvent of crystallization methanol. Yield $89 \%$. Yellow solid, $\mathrm{mp}>300{ }^{\circ} \mathrm{C}$. IR $(\mathrm{KBr}) v_{\max }: 1716,1676(\mathrm{C}=\mathrm{O})$, $1645(\mathrm{C}=\mathrm{N}), 1582 \& 1489(\mathrm{C}=\mathrm{C}, \mathrm{Ar}) \mathrm{cm}^{-1} .{ }^{1} \mathrm{H}$ NMR $\left(500 \mathrm{MH} z\right.$, DMSO- $\left.d_{6}\right) \delta: 2.82(\mathrm{~s}, 2 \mathrm{H}, 2 \times \mathrm{CH}), 3.18(\mathrm{~s}$, $\left.3 \mathrm{H}, \mathrm{CH}_{3}\right), 4.64(\mathrm{~s}, 2 \mathrm{H}, 2 \times \mathrm{CH}), 7.03-8.49(\mathrm{~m}, 14 \mathrm{H}, \mathrm{Ar}-$ $\mathrm{H}), 8.30(\mathrm{~s}, 1 \mathrm{H}, \mathrm{Ar}-\mathrm{H}) .{ }^{13} \mathrm{C}$ NMR $\left(125 \mathrm{MHz}, \mathrm{DMSO}-d_{6}\right) \delta$ : $21.15,47.64,48.29,112.02,112.09,121.82,122.28$, $122.66,123.26,123.80,124.84,125.20,125.62,132.49$, $135.04,141.44,143.65,148.25,155.32,173.44$, APCI-MS

$\mathrm{m} / \mathrm{z} \quad 467.4\left(\mathrm{M}^{+}+\mathrm{H}, \quad 100 \%\right), 274.8$

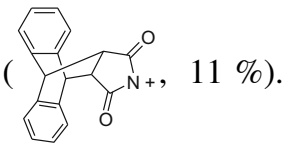

Elemental Anal. Calcd for $\mathrm{C}_{32} \mathrm{H}_{22} \mathrm{~N}_{2} \mathrm{O}_{2}$ : C 82.40, H 4.72, N 6.00; Found C 82.53, H 4.82, N $6.09 \%$.

$\mathrm{N}$-(4-methoxyacridin-9-yl)-9,10-dihydro-9,10-

ethanoanthracene-11,12-dicarboximide (3c)

Solvent of crystallization methanol. Yield $91 \%$. Yellow solid, mp 206-207 ${ }^{\circ} \mathrm{C}$. IR (KBr) v vax $1676(\mathrm{C}=\mathrm{O}), 1635$ $(\mathrm{C}=\mathrm{N}), 1588 \& 1516(\mathrm{C}=\mathrm{C}, \mathrm{Ar}) \mathrm{cm}^{-1} .{ }^{1} \mathrm{H}$ NMR $(500 \mathrm{MH} z$, DMSO- $\left.d_{6}\right) \delta: 2.93(\mathrm{~s}, 2 \mathrm{H}, 2 \times \mathrm{CH}), 4.04\left(\mathrm{~s}, 3 \mathrm{H}, \mathrm{OCH}_{3}\right)$, $4.66(\mathrm{~s}, 2 \mathrm{H}, 2 \times \mathrm{CH}), 7.03-8.52(\mathrm{~m}, 15 \mathrm{H}, \mathrm{Ar}-\mathrm{H}) .{ }^{13} \mathrm{C}$ NMR $\left(125 \mathrm{MHz}\right.$, DMSO- $\left.d_{6}\right) \quad \delta: 48.20,48.85,56.14$, $111.59,111.74,112.17,114.72,123.21,123.35,123.69$, $123.77,124.77,125.39,125.70,132.78,134.98,141.22$, 143.42, 154.59, 174.63, APCI-MS $m / z 483.4\left(\mathrm{M}^{+}+\mathrm{H}\right.$,

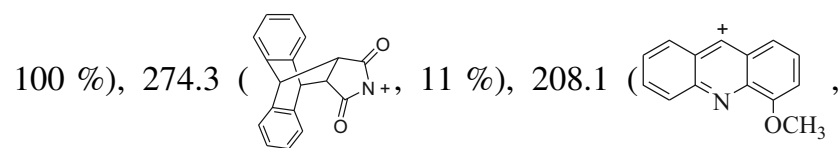

$3 \%$ ). Elemental Anal. Calcd for $\mathrm{C}_{32} \mathrm{H}_{22} \mathrm{~N}_{2} \mathrm{O}_{3}: \mathrm{C} 79.66, \mathrm{H}$ 4.56, N 5.80; Found C 79.78, H 4.64, N $5.89 \%$.

$N$-(4-ethoxyacridin-9-yl)-9,10-dihydro-9,10ethanoanthracene-11,12-dicarboximide (3d)

Solvent of crystallization methanol. Yield $92 \%$. Yellow solid, mp $185-186{ }^{\circ} \mathrm{C}$. IR $(\mathrm{KBr}) v_{\max }: 1671(\mathrm{C}=\mathrm{O}), 1633$ $(\mathrm{C}=\mathrm{N}), 1588 \& 1517(\mathrm{C}=\mathrm{C}, \mathrm{Ar}) \mathrm{cm}^{-1} .{ }^{1} \mathrm{H}$ NMR $(500 \mathrm{MH} z$, DMSO- $\left.d_{6}\right) \delta: 1.48-1.51\left(\mathrm{t}, 3 \mathrm{H}, J=7 \mathrm{~Hz}, \mathrm{CH}_{3}\right), 2.92(\mathrm{~s}$, $2 \mathrm{H}, 2 \times \mathrm{CH}), 4.26-4.30\left(\mathrm{q}, 2 \mathrm{H}, J=7 \& 14 \mathrm{~Hz}, \mathrm{OCH}_{2}\right)$, $4.66(\mathrm{~s}, 2 \mathrm{H}, 2 \times \mathrm{CH}), 7.03-8.50(\mathrm{~m}, 15 \mathrm{H}, \mathrm{Ar}-\mathrm{H}) .{ }^{13} \mathrm{C}$ NMR (125 MHz, DMSO- $\left.d_{6}\right) \delta: 14.18,48.12,48.72,64.60$, $111.84,112.30,112.39,114.61,122.63,123.23,123.41$, $123.74,124.78,125.40,125.71,132.21,135.31,141.21$, 143.42, 154.71, 174.39, APCI-MS $m / z 497.0\left(\mathrm{M}^{+}+\mathrm{H}\right.$,

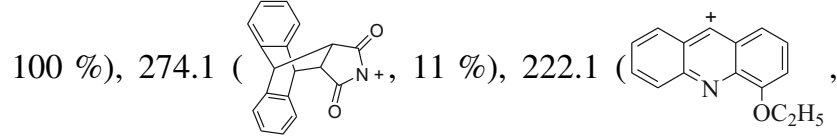
$4 \%$ ). Elemental Anal. Calcd for $\mathrm{C}_{33} \mathrm{H}_{24} \mathrm{~N}_{2} \mathrm{O}_{3}: \mathrm{C} 79.83, \mathrm{H}$ 4.83, N 5.64; Found C 79.91, H 4.93, N $5.70 \%$.

$N$-(4-methylacridin-9-yl)-9,10-dihydro-9,10ethanoanthracene-11,12-dicarboximide (3e)

Solvent of crystallization methanol. Yield $92 \%$. Yellow solid, mp 225-227 ${ }^{\circ} \mathrm{C}$. IR (KBr) v $v_{\max }: 1676(\mathrm{C}=\mathrm{O}), 1633$ $(\mathrm{C}=\mathrm{N}), 1573,1514 \& 1467(\mathrm{C}=\mathrm{C}, \mathrm{Ar}) \mathrm{cm}^{-1} .{ }^{1} \mathrm{H}$ NMR $\left(500 \mathrm{MH} z, \mathrm{DMSO}-d_{6}\right) \delta: 2.70\left(\mathrm{~s}, 3 \mathrm{H}, \mathrm{CH}_{3}\right), 2.96(\mathrm{~s}, 2 \mathrm{H}$, $2 \times \mathrm{CH}), 4.60(\mathrm{~s}, 2 \mathrm{H}, 2 \times \mathrm{CH}), 7.02-8.43(\mathrm{~m}, 15 \mathrm{H}, \mathrm{Ar}-$ H). ${ }^{13} \mathrm{C}$ NMR $\left(125 \mathrm{MHz}, \mathrm{DMSO}-d_{6}\right) \delta: 18.55,46.97$, $47.69,112.31,112.49,121.44,121.84,122.32,123.35$, $123.42,124.90,125.24,125.70,131.23,135.03,141.25$, $143.49,148.84,155.23,172.96$, APCI-MS $m / z 467.2$ $\left(\mathrm{M}^{+}+\mathrm{H}, 100 \%\right), 274.5$ ( Elemental Anal. Calcd for $\mathrm{C}_{32} \mathrm{H}_{22} \mathrm{~N}_{2} \mathrm{O}_{2}$ : C 82.40, H 4.72, N 6.00; Found C 82.52, H 4.79, N $6.10 \%$.

N-(3-methoxyacridin-9-yl)-9,10-dihydro-9,10ethanoanthracene-11,12-dicarboximide (3f)

Solvent of crystallization methanol. Yield $90 \%$. Yellow solid, mp 230-231 ${ }^{\circ} \mathrm{C}$. IR (KBr) v $v_{\max }: 1669(\mathrm{C}=\mathrm{O}), 1639$ 
$(\mathrm{C}=\mathrm{N})$, 1583, 1552, $1497(\mathrm{C}=\mathrm{C}$, Ar $) \mathrm{cm}^{-1} \cdot{ }^{1} \mathrm{H}$ NMR $\left(500 \mathrm{MHz}, \mathrm{DMSO}-d_{6}\right) \delta: 2.93(\mathrm{~s}, 2 \mathrm{H}, 2 \times \mathrm{CH}), 4.26(\mathrm{~s}$, $\left.3 \mathrm{H}, \mathrm{OCH}_{3}\right), 4.65(\mathrm{~s}, 2 \mathrm{H}, 2 \times \mathrm{CH}), 7.15(\mathrm{~s}, 1 \mathrm{H}, \mathrm{Ar}-\mathrm{H})$, 7.03-8.44 (m, 14H, Ar-H). ${ }^{13} \mathrm{C}$ NMR (125 MHz, DMSO$\left.d_{6}\right) \delta: 48.21,48.85,56.17,111.70,111.74,112.21,114.72$, $123.21,123.39,123.69,123.77,124.79,125.38,125.74$, $132.76,134.96,141.23,143.44,154.69,174.69$, APCI-MS $m / z \quad 483.0\left(\mathrm{M}^{+}+\mathrm{H}, \quad 100 \%\right), 274.1$

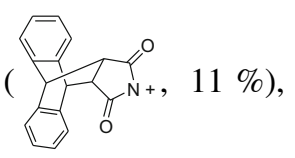
208.3 . Elemental Anal. Calcd for $\mathrm{C}_{32} \mathrm{H}_{22} \mathrm{~N}_{2} \mathrm{O}_{3}$ : C 79.66, H 4.56, N 5.80; Found C 79.72, H 4.64, N $5.90 \%$.

$N$-(2-methoxyacridin-9-yl)-9,10-dihydro-9,10ethanoanthracene-11,12-dicarboximide (3g)

Solvent of crystallization methanol. Yield $94 \%$. Yellow solid, mp 183-185 ${ }^{\circ} \mathrm{C}$. IR (KBr) v $v_{\max }: 1667$ (C=O), 1639 $(\mathrm{C}=\mathrm{N}), 1583,1552,1497(\mathrm{C}=\mathrm{C}, \mathrm{Ar}) \mathrm{cm}^{-1} \cdot{ }^{1} \mathrm{H}$ NMR $\left(500 \mathrm{MHz}, \mathrm{DMSO}-d_{6}\right) \delta: 2.95(\mathrm{~s}, 2 \mathrm{H}, 2 \times \mathrm{CH}), 3.94(\mathrm{~s}$, $\left.3 \mathrm{H}, \mathrm{OCH}_{3}\right), 4.63(\mathrm{~s}, 2 \mathrm{H}, 2 \times \mathrm{CH}), 7.03-8.45(\mathrm{~m}, 15 \mathrm{H}, \mathrm{Ar}-$ H). ${ }^{13} \mathrm{C}$ NMR $\left(125 \mathrm{MHz}, \mathrm{DMSO}-d_{6}\right) \delta: 48.21,48.83$, $56.16,111.59,111.74,112.17,114.72,123.26,123.35$, $123.69,123.76,124.77,125.39,125.70,133.86,134.98$, $141.21,143.43,154.43,174.65$, APCI-MS $m / z \quad 483.7$

$\left(\mathrm{M}^{+}+\mathrm{H}, \quad 100 \%\right), \quad 274.2$

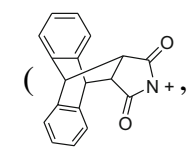

$11 \%), \quad 208.1$<smiles></smiles>

Elemental Anal. Calcd for $\mathrm{C}_{32} \mathrm{H}_{22} \mathrm{~N}_{2} \mathrm{O}_{3}$ : C 79.66, $\mathrm{H}$ 4.56, N 5.80; Found C 79.76, H 4.64, N $5.88 \%$.

$N$-(acridin-9-yl)-9,10-dihydro-9,10-ethanoanthracene11,12-dicarboximide (3h)

Solvent of crystallization methanol. Yield $91 \%$. Yellow solid, $\mathrm{mp}>300^{\circ} \mathrm{C}$. IR $(\mathrm{KBr}) v_{\max }: 1682(\mathrm{C}=\mathrm{O}), 1648$ $(\mathrm{C}=\mathrm{N}), 1581 \& 1487(\mathrm{C}=\mathrm{C}, \mathrm{Ar}) \mathrm{cm}^{-1} .{ }^{1} \mathrm{H} \mathrm{NMR}(500 \mathrm{MHz}$, DMSO- $\left.d_{6}+\mathrm{D}_{2} \mathrm{O}\right) \delta: 2.92(\mathrm{~s}, 2 \mathrm{H}, 2 \times \mathrm{CH}), 4.61(\mathrm{~s}, 2 \mathrm{H}$, $2 \times \mathrm{CH}), \quad 7.03-8.48 \quad(\mathrm{~m}, \quad 16 \mathrm{H}, \quad \mathrm{Ar}-\mathrm{H}) . \quad{ }^{13} \mathrm{C} \quad \mathrm{NMR}$ (125 MHz, DMSO- $d_{6}$ ) $\delta: 47.79,48.44,111.89,123.04$, $123.27,123.77,124.82,125.34,125.72,133.00,141.24$, 143.45, 174.00, APCI-MS m/z $453.7\left(\mathrm{M}^{+}+\mathrm{H}, 100 \%\right)$,

274.1

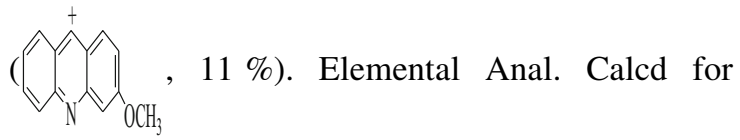

$\mathrm{C}_{31} \mathrm{H}_{20} \mathrm{~N}_{2} \mathrm{O}_{2}$ : C 82.30, H 4.42, N 6.19; Found C 82.42, H 4.54, N $6.27 \%$.

General procedure for synthesis of acridine derivatives (4a-4d, 5a-5d \& 6a-6d)

Synthesis of 2-(3-methylacridin-9-yl) isoindoline-1,3-dione (4a)

9-Amino-3-methylacridine (1a; $208 \mathrm{mg} ; 1 \mathrm{mmol})$ and phthalic anhydride (148 $\mathrm{mg} ; 1 \mathrm{mmol})$ were mixed together and then subjected to microwave irradiation at $120^{\circ} \mathrm{C}$ for 5 min. TLC of reaction mixture over silica gel $\mathrm{G}$ using $\mathrm{CHCl}_{3}: \mathrm{MeOH}(8.5: 1.5)$ as mobile phase showed the presence of starting materials. This reaction mixture was further irradiated for $5 \mathrm{~min}$ at $120^{\circ} \mathrm{C}$. TLC of reaction mixture showed completion of reaction. This crude product was crystallized from methanol to give pure product 4 a. Yield $310 \mathrm{mg}(\approx 93 \%)$. Yellow solid, mp 195-197 ${ }^{\circ} \mathrm{C}$. IR $(\mathrm{KBr}) v_{\max }: 1653(\mathrm{C}=\mathrm{O}), 1588,1549 \& 1481(\mathrm{C}=\mathrm{C}, \mathrm{Ar})$ $\mathrm{cm}^{-1} .{ }^{1} \mathrm{H}$ NMR (500 MHz, DMSO-d $) \delta: 2.99(\mathrm{~s}, 3 \mathrm{H}$, $\left.\mathrm{CH}_{3}\right), 7.33-8.59(\mathrm{~m}, 11 \mathrm{H}, \mathrm{Ar}-\mathrm{H}) .{ }^{13} \mathrm{C} \mathrm{NMR}(125 \mathrm{MHz}$, DMSO- $\left.d_{6}\right) \delta: 23.66,111.95,113.26,117.14,118.68$, $124.20,124.89,127.30,128.60,130.97,132.89,135.18$, 135.74, 137.89, 138.98, 141.63, 159.73, 168.83, APCI-MS: $\mathrm{m} / \mathrm{z} \quad 339.1\left(\mathrm{M}^{+}+\mathrm{H}, \quad 100 \%\right), 192.2$ $11 \%$ ). Elemental Anal. Calcd. for $\mathrm{C}_{22} \mathrm{H}_{14} \mathrm{~N}_{2} \mathrm{O}_{2}$ : C 78.10, H 4.14, N 8.28; Found C 78.19, H 4.21, N $8.38 \%$.

Alternatively, above reaction mixture was subjected to microwave irradiation at a power level of level of $600 \mathrm{Watt}$ for $5 \mathrm{~min}$. TLC of reaction mixture over silica gel $\mathrm{G}$ using $\mathrm{CHCl}_{3}: \mathrm{MeOH}(8.5: 1.5)$ as mobile phase showed the presence of starting materials. This reaction mixture was further irradiated for $5 \mathrm{~min}$. TLC of reaction mixture showed completion of reaction. This crude product was crystallized from methanol to give pure product 4a. Yield $306 \mathrm{mg}$ ( $\approx 90 \%$ ).

Similarly, other acridine derivatives $4 \mathbf{b}-\mathbf{4 d}, \mathbf{5 a}-\mathbf{5 d}$, and 6a-6d were synthesized. Physical constants and spectral data of $\mathbf{4 b}-\mathbf{4 d}, \mathbf{5 a}-\mathbf{5 d}$, and $\mathbf{6 a - 6 d}$ are summarized below.

\section{2-(2-Methylacridin-9-yl)isoindoline-1,3-dione (4b)}

Microwave irradiation at $120{ }^{\circ} \mathrm{C}$ for $5 \times 2$ min (at power level of $600 \mathrm{Watt}$ for $5 \times 2 \mathrm{~min}$ ). Solvent of crystallization methanol. Yield $87 \%$. Greenish yellow solid, mp 163-165 ${ }^{\circ} \mathrm{C}$. IR (KBr) v vax $_{\max }: 1687$ (C=O), 1586, 1551, 1490 $(\mathrm{C}=\mathrm{C}, \mathrm{Ar}) \mathrm{cm}^{-1} .{ }^{1} \mathrm{H}$ NMR $\left(500 \mathrm{MHz}, \mathrm{DMSO}-d_{6}\right) \delta: 2.98$ $\left(\mathrm{s}, 3 \mathrm{H}, \mathrm{CH}_{3}\right), 7.33-8.54(\mathrm{~m}, 11 \mathrm{H}, \mathrm{Ar}-\mathrm{H}) .{ }^{13} \mathrm{C}$ NMR $\left(125 \mathrm{MHz}, \mathrm{DMSO}-d_{6}\right) \delta$ : 21.48, 111.96, 112.02, 119.47, 
$122.59,123.48,124.24,124.98,130.76,132.89,134.06$, $135.43,135.76,137.98,138.37,139.76,157.51,168.53$,

GC-MS: $m / z 338\left(\mathrm{M}^{+}, 100 \%\right), 192$, $5 \%), 76$ $\mathrm{C}_{22} \mathrm{H}_{14} \mathrm{~N}_{2} \mathrm{O}_{2} \mathrm{C} 78.10, \mathrm{H} 4.14, \mathrm{~N}$ 8.28; Found $\mathrm{C} 78.25, \mathrm{H}$ 4.21, N $8.34 \%$.

\section{2-(4-Methoxyacridin-9-yl)isoindoline-1, 3-dione (4c)}

Microwave irradiation at $120{ }^{\circ} \mathrm{C}$ for $7 \times 2 \mathrm{~min}$ (at power level of $600 \mathrm{Watt}$ for $7 \times 2 \mathrm{~min}$ ). Solvent of crystallization methanol. Yield $90 \%$. Yellow solid, mp 258-260 ${ }^{\circ} \mathrm{C}$. IR $(\mathrm{KBr}) v_{\max }: 1663(\mathrm{C}=\mathrm{O}), 1591,1552,1510(\mathrm{C}=\mathrm{C}, \mathrm{Ar})$ $\mathrm{cm}^{-1} .{ }^{1} \mathrm{H}$ NMR (500 MHz, DMSO-d $) \delta: 4.00(\mathrm{~s}, 3 \mathrm{H}$, $\left.\mathrm{OCH}_{3}\right), 7.33-8.42(\mathrm{~m}, 11 \mathrm{H}, \mathrm{Ar}-\mathrm{H}) .{ }^{13} \mathrm{C} \mathrm{NMR}(125 \mathrm{MHz}$, DMSO- $\left.d_{6}\right) \quad \delta: 56.88,111.84,112.29,113.44,116.46$, $119.81,124.18,124.42,124.58,131.11,131.17,132.94$, 134.91, 135.57, 139.25, 148.43, 157.72, 169.15, GC-MS: $\mathrm{m} / \mathrm{z} 355\left(\mathrm{M}^{+\bullet}+1,3 \%\right), 354\left(\mathbf{M}^{+\bullet}, 24 \%\right), 353\left(\mathbf{M}^{+\bullet}-\mathrm{H}\right.$,

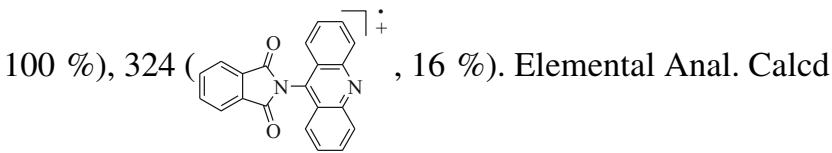

for $\mathrm{C}_{22} \mathrm{H}_{14} \mathrm{~N}_{2} \mathrm{O}_{3} \mathrm{C} 74.57, \mathrm{H} 3.95, \mathrm{~N} 7.90$; Found C 74.63, $\mathrm{H} 4.08, \mathrm{~N} 8.04 \%$.

\section{2-(4-Ethoxyacridin-9-yl)isoindoline-1,3-dione (4d)}

Microwave irradiation at $120{ }^{\circ} \mathrm{C}$ for $6 \times 2 \mathrm{~min}$ (at power level of $600 \mathrm{Watt}$ for $6 \times 2 \mathrm{~min}$ ). Solvent of crystallization methanol. Yield $92 \%$. Yellow solid, mp 239-241 ${ }^{\circ} \mathrm{C}$. IR $(\mathrm{KBr}) v_{\max }: 1669(\mathrm{C}=\mathrm{O}), 1631(\mathrm{C}=\mathrm{N}), 1587,1549$ \& 1512 $(\mathrm{C}=\mathrm{C}, \mathrm{Ar}) \mathrm{cm}^{-1} .{ }^{1} \mathrm{H}$ NMR $\left(500 \mathrm{MH} z, \mathrm{DMSO}-d_{6}\right) \delta$ : $1.50-1.53\left(\mathrm{t}, 3 \mathrm{H}, J=7 \mathrm{~Hz}, \mathrm{CH}_{3}\right), 4.38-4.43(\mathrm{q}, 2 \mathrm{H}$, $\left.J=7,14 \mathrm{~Hz}, \mathrm{OCH}_{2}\right), 7.48-8.62(\mathrm{~m}, 11 \mathrm{H}, \mathrm{Ar}-\mathrm{H}) .{ }^{13} \mathrm{C}$ NMR (125 MHz, DMSO- $\left.d_{6}\right) \delta: 14.75,65.48,112.23$, $112.83,114.47,115.60,120.35,124.31,124.62,124.77$, $130.80,131.80,132.93,135.40,135.66,139.75,147.85$, 158.08, 168.59, GC-MS: $m / z 368\left(\mathrm{M}^{+}, 5 \%\right), 323\left(\mathrm{M}^{+}-\right.$ $\left.\mathrm{OC}_{2} \mathrm{H}_{5}, 3 \%\right), 222(\underbrace{+}_{\mathrm{O}}, 20 \%), 146\left(\mathrm{~N}_{\mathrm{N}^{+}}\right.$, $30 \%), 76$, Elemental Anal. Calcd for $\mathrm{C}_{23} \mathrm{H}_{16} \mathrm{~N}_{2} \mathrm{O}_{3} \mathrm{C} 75.00, \mathrm{H} 4.34, \mathrm{~N} 7.60$; Found $\mathrm{C} 75.12, \mathrm{H}$ 4.41, N $7.73 \%$.
2-(3-Methylacridin-9-yl)-3a,4,7,7a-tetrahydro-2Hisoindole-1, 3-dione (5a)

Microwave irradiation at $120^{\circ} \mathrm{C}$ for $5 \times 2$ min (at power level of 600 Watt for $5 \times 2 \mathrm{~min}$ ). Solvent of crystallization methanol. Yield $88 \%$. Yellow solid, mp 200-202 ${ }^{\circ} \mathrm{C}$. IR $(\mathrm{KBr}) v_{\max }: 1670(\mathrm{C}=\mathrm{O}), 1631(\mathrm{C}=\mathrm{N}), 1587,1549 \& 1512$ $(\mathrm{C}=\mathrm{C}, \mathrm{Ar}) \mathrm{cm}^{-1} .{ }^{1} \mathrm{H}$ NMR $(500 \mathrm{MH} z, \text { DMSO-d })_{6} \delta$ : 2.08-2.12 (dd, $2 \mathrm{H}, J=4.5,16 \mathrm{~Hz}, \mathrm{CH}_{2}$ ), 2.31-2.36 (dd, $\left.2 \mathrm{H}, J=6,15.5 \mathrm{~Hz}, \mathrm{CH}_{2}\right), 2.70-2.73(\mathrm{t}, 2 \mathrm{H}, J=5.5 \mathrm{~Hz}$, $2 \times \mathrm{CH}), 2.98\left(\mathrm{~s}, 3 \mathrm{H}, \mathrm{CH}_{3}\right), 5.57(\mathrm{~s}, 2 \mathrm{H}, \mathrm{CH}=\mathrm{CH})$, 7.24-8.55 (m, 7H, Ar-H). ${ }^{13} \mathrm{C}$ NMR (125 MHz, DMSO$\left.d_{6}\right) \delta: 21.89,28.18,41.76,112.69,113.09,115.68,123.60$, $124.08,125.59$, 126.65, 127.46, 128.30, 129.66, 134.25, 138.29, 139.16, 155.54, 175.14, GC-MS: m/z $342\left(\mathrm{M}^{+}\right.$; $100 \%), 192$, Elemental Anal. Calcd for $\mathrm{C}_{22} \mathrm{H}_{18} \mathrm{~N}_{2} \mathrm{O}_{2} \mathrm{C} 77.19$, H 5.26, N 8.18; Found $\mathrm{C}$ 77.30, H 5.32, N $8.25 \%$.

2-(2-Methylacridin-9-yl)-3a,4,7,7a-tetrahydro- $2 \mathrm{H}$ isoindole-1, 3-dione (5b)

Microwave irradiation at $120{ }^{\circ} \mathrm{C}$ for $6 \times 2$ min (at power level of $600 \mathrm{Watt}$ for $6 \times 2 \mathrm{~min}$ ). Solvent of crystallization methanol. Yield $89 \%$. Yellow solid, mp 211-213 ${ }^{\circ} \mathrm{C}$. IR (KBr) $v_{\max }: 1669(\mathrm{C}=\mathrm{O}), 1631(\mathrm{C}=\mathrm{N}), 1587,1549 \& 1512$ $(\mathrm{C}=\mathrm{C}$, Ar $) \mathrm{cm}^{-1} .{ }^{1} \mathrm{H}$ NMR $\left(500 \mathrm{MHz}, \mathrm{DMSO}-d_{6}\right) \delta$ : 2.08-2.12 (dd, $2 \mathrm{H}, J=4.5,16 \mathrm{~Hz}, \mathrm{CH}_{2}$ ), 2.31-2.36 (dd, $\left.2 \mathrm{H}, J=6.5,15.5 \mathrm{~Hz}, \mathrm{CH}_{2}\right), 2.70-2.73(\mathrm{t}, 2 \mathrm{H}, J=7 \mathrm{~Hz}$, $2 \times \mathrm{CH}), 2.98\left(\mathrm{~s}, 3 \mathrm{H}, \mathrm{CH}_{3}\right), 5.57(\mathrm{~s}, 2 \mathrm{H}, \mathrm{CH}=\mathrm{CH})$, 7.24-8.57 (m, 7H, Ar-H). ${ }^{13} \mathrm{C}$ NMR (125 MHz, DMSO$\left.d_{6}\right) \delta: 21.90,28.26,41.83,112.74,113.10,115.66,123.62$, $124.10,125.60,126.61,127.54,128.36,129.72,134.30$, $138.34,139.22,154.94,175.17$, APCI-MS m/z 343.1 $\left(\mathrm{M}^{+}+\mathrm{H}, 100 \%\right), 192.2$ ( Elemental Anal. Calcd for $\mathrm{C}_{22} \mathrm{H}_{18} \mathrm{~N}_{2} \mathrm{O}_{2}$ :C 77.19, H 5.26, $\mathrm{N} 8.18$; Found C 77.26, H 5.29, N $8.33 \%$.

2-(4-Methoxyacridin-9-yl)-3a,4,7,7a-tetrahydro-2Hisoindole-1, 3-dione $(5 \mathrm{c})$

Microwave irradiation at $120^{\circ} \mathrm{C}$ for $6 \times 2$ min (at power level of $600 \mathrm{Watt}$ for $6 \times 2 \mathrm{~min}$ ). Solvent of crystallization methanol. Yield $89 \%$. Yellow solid, mp $280{ }^{\circ} \mathrm{C}$. IR $(\mathrm{KBr})$ $v_{\max }: 1697(\mathrm{C}=\mathrm{O}), 1623,1573 \& 1528(\mathrm{C}=\mathrm{C}, \mathrm{Ar}) \mathrm{cm}^{-1} \cdot{ }^{1} \mathrm{H}$ NMR $(500 \mathrm{MHz}, \text { DMSO-d })_{6} \delta: 2.22-2.27(\mathrm{dd}, 2 \mathrm{H}, J=5$, $\left.16 \mathrm{~Hz}, \mathrm{CH}_{2}\right), 2.38-2.43\left(\mathrm{dd}, 2 \mathrm{H}, J=5,16 \mathrm{~Hz}, \mathrm{CH}_{2}\right)$, 2.86-2.88 (t, $2 \mathrm{H}, J=5.5 \mathrm{~Hz}, 2 \times \mathrm{CH}), 4.05(\mathrm{~s}, 3 \mathrm{H}$, 
$\left.\mathrm{OCH}_{3}\right), 5.62(\mathrm{~s}, 2 \mathrm{H}, \mathrm{CH}=\mathrm{CH}), 7.18-8.23(\mathrm{~m}, 7 \mathrm{H}, \mathrm{Ar}-\mathrm{H})$. ${ }^{13} \mathrm{C}$ NMR (125 MHz, DMSO- $\left.d_{6}\right) \delta: 28.16,41.74,56.79$, $112.65,113.07,115.65,123.59,124.05,125.49,126.63$, $127.45,128.32,129.63,134.20,138.26,139.17,155.44$, 175.17, APCI-MS: $m / z 359.1\left(\mathrm{M}^{+}+\mathrm{H}, 100 \%\right), 208.1$ , Elemental Anal. Calcd for $\mathrm{C}_{22} \mathrm{H}_{18} \mathrm{~N}_{2} \mathrm{O}_{3}$ : C 73.74, H 5.02, N 7.82; Found C 73.83, H $5.09, \mathrm{~N} 7.91 \%$.

2-(4-Ethoxyacridin-9-yl)-3a,4,7,7a-tetrahydro-2Hisoindole-1, 3-dione $(\mathbf{5 d})$

Microwave irradiation at $120{ }^{\circ} \mathrm{C}$ for $6 \times 2$ min (at power level of 600 Watt for $6 \times 2 \mathrm{~min}$ ). Solvent of crystallization methanol. Yield $91 \%$. Yellow solid, mp $198-200{ }^{\circ} \mathrm{C}$. IR $(\mathrm{KBr}) v_{\max }: 1639(\mathrm{C}=\mathrm{O}), 1572 \& 1511(\mathrm{C}=\mathrm{C}, \mathrm{Ar}) \mathrm{cm}^{-1} .{ }^{1} \mathrm{H}$ NMR $\left(500 \mathrm{MH} z\right.$, DMSO- $\left.d_{6}\right) \quad \delta: 1.47-1.49 \quad(\mathrm{t}, 3 \mathrm{H}$, $J=7 \mathrm{~Hz}, \mathrm{CH}_{3}$ ), 2.06-2.09 (dd, $2 \mathrm{H}, J=5 \& 10.5 \mathrm{~Hz}$, $\mathrm{CH}_{2}$ ), 2.31-2.35 (dd, $2 \mathrm{H}, J=5.5 \& 14 \mathrm{~Hz},-\mathrm{CH}_{2}$ ), 2.69 (s, $2 \mathrm{H}, 2 \times \mathrm{CH}), 4.32-4.35\left(\mathrm{q}, 2 \mathrm{H}, J=6.5,13.5 \mathrm{~Hz}, \mathrm{OCH}_{2}\right)$, $5.66(\mathrm{~s}, 2 \mathrm{H}, \mathrm{CH}=\mathrm{CH}), 7.40-8.56(\mathrm{~m}, 7 \mathrm{H}, \mathrm{Ar}-\mathrm{H}) .{ }^{13} \mathrm{C} \mathrm{NMR}$ $\left(125 \mathrm{MHz}, \mathrm{DMSO}-d_{6}\right) \delta: 14.85,28.06,41.76,56.78$, $112.62,113.08,115.65,123.57,124.03,125.49,126.62$, $127.42,128.32,129.62,134.17,138.28,139.19,155.42$, 175.12, APCI-MS: $m / z, 373.1\left(\mathrm{M}^{+}+\mathrm{H}, 100 \%\right), 222.3$ , $7 \%$ ). Elemental Anal. Calcd for $\mathrm{C}_{23} \mathrm{H}_{20} \mathrm{~N}_{2} \mathrm{O}_{3}$ : C 74.19, H 5.37, N 7.52; Found C 74.27, H 5.43 , N $7.59 \%$.

\section{1-(3-Methylacridin-9-yl)-1H-pyrrole-2,5-dione (6a)}

Microwave irradiation at $120{ }^{\circ} \mathrm{C}$ for $6 \times 2$ min (at power level of 600 Watt for $6 \times 2 \mathrm{~min}$ ). Solvent of crystallization methanol. Yield $91 \%$. Yellow solid, mp 196-198 ${ }^{\circ} \mathrm{C}$. IR (KBr) v $v_{\max }: 1644(\mathrm{C}=\mathrm{O}), 1580,1486(\mathrm{C}=\mathrm{C}, \mathrm{Ar}) \mathrm{cm}^{-1} .{ }^{1} \mathrm{H}$ NMR (500 MHz, DMSO- $\left.d_{6}\right) \delta: 3.00\left(\mathrm{~s}, 3 \mathrm{H}, \mathrm{CH}_{3}\right), 6.06(\mathrm{~s}$, $2 \mathrm{H}, \mathrm{CH}=\mathrm{CH}), 7.33-8.52(\mathrm{~m}, 7 \mathrm{H}, \mathrm{Ar}-\mathrm{H}) .{ }^{13} \mathrm{C} \mathrm{NMR}$ $\left(125 \mathrm{MHz}, \mathrm{DMSO}-d_{6}\right) \delta: 23.65,111.78,113.10,116.94$, $118.47,124.23,124.82,127.34,134.45,135.23,135.80$, $137.84,138.75,141.40,159.71,167.78$, APCI-MS: $m / z$

$289.0\left(\mathrm{M}^{+}+\mathrm{H}, 100 \%\right), 192.1$ ( Elemental Anal. Calcd for $\mathrm{C}_{18} \mathrm{H}_{12} \mathrm{~N}_{2} \mathrm{O}_{2}$ : C 75.00, H 4.16, N 9.72; Found C 75.12, H 4.23, N $9.81 \%$.

\section{1-(2-Methylacridin-9-yl)-1H-pyrrole-2,5-dione (6b)}

Microwave irradiation at $120{ }^{\circ} \mathrm{C}$ for $5 \times 2$ min (at power level of $600 \mathrm{Watt}$ for $5 \times 2 \mathrm{~min}$ ). Solvent of crystallization methanol. Yield $90 \%$. Greenish yellow solid, $\mathrm{mp}$ 250-252 ${ }^{\circ} \mathrm{C}$. IR (KBr) v $v_{\max }: 1642(\mathrm{C}=\mathrm{O}), 1584,1492$ $(\mathrm{C}=\mathrm{C}, \mathrm{Ar}) \mathrm{cm}^{-1} .{ }^{1} \mathrm{H}$ NMR $\left(500 \mathrm{MH} z\right.$, DMSO- $\left.d_{6}+\mathrm{D}_{2} \mathrm{O}\right)$ $\delta: 2.48\left(\mathrm{~s}, 3 \mathrm{H}, \mathrm{CH}_{3}\right), 6.10(\mathrm{~s}, 2 \mathrm{H}, \mathrm{CH}=\mathrm{CH}), 7.53-8.51(\mathrm{~m}$, $7 \mathrm{H}, \mathrm{Ar}-\mathrm{H}) .{ }^{13} \mathrm{C}$ NMR $\left(125 \mathrm{MHz}, \mathrm{DMSO}-d_{6}\right) \delta: 21.46$, $111.90,111.96,119.18,119.28,124.29,126.99,127.14$, $134.14,135.70,135.90,137.69,138.09,139.50,157.69$, 167.67, APCI-MS: m/z $289.1\left(\mathrm{M}^{+}+\mathrm{H}, 100 \%\right), 192.1$ Elemental Anal. Calcd for $\mathrm{C}_{18} \mathrm{H}_{12} \mathrm{~N}_{2} \mathrm{O}_{2}$ : C 75.00, H 4.16, N 9.72; Found C 75.09, H 4.23, N $9.79 \%$.

\section{1-(4-Methoxyacridin-9-yl)-1H-pyrrole-2,5-dione (6c)}

Microwave irradiation at $120{ }^{\circ} \mathrm{C}$ for $7 \times 2 \mathrm{~min}$ (at power level of $600 \mathrm{Watt}$ for $7 \times 2 \mathrm{~min}$ ). Solvent of crystallization methanol. Yield $90 \%$. Yellow solid, mp $279{ }^{\circ} \mathrm{C}$. IR $(\mathrm{KBr})$ $v_{\max }: 1717(\mathrm{C}=\mathrm{O}), 1623,1576,1528,1470(\mathrm{C}=\mathrm{C}, \mathrm{Ar})$ $\mathrm{cm}^{-1} .{ }^{1} \mathrm{H}$ NMR $\left(500 \mathrm{MH} z\right.$, DMSO-d $\left.d_{6}\right) \delta: 4.05(\mathrm{~s}, 3 \mathrm{H}$, $\left.\mathrm{OCH}_{3}\right), 6.12(\mathrm{~s}, 2 \mathrm{H}, \mathrm{CH}=\mathrm{CH}), 7.18-8.23(\mathrm{~m}, 7 \mathrm{H}, \mathrm{Ar}-\mathrm{H})$. ${ }^{13} \mathrm{C}$ NMR (125 MHz, DMSO- $\left.d_{6}\right) \delta: 56.69,112.80,118.78$, $121.00,121.04,121.57,121.74,126.20,129.07,131.99$, 132.32, 133.58, 141.14, 148.29, 155.23, 166.22, APCI-MS:

m/z $305.0\left(\mathrm{M}^{+}+\mathrm{H}, 100 \%\right), 208.1$, $\left.7 \%\right)$.

Elemental Anal. Calcd for $\mathrm{C}_{18} \mathrm{H}_{12} \mathrm{~N}_{2} \mathrm{O}_{3}: \mathrm{C} 71.05, \mathrm{H} 3.94, \mathrm{~N}$ 9.21; Found C 71.11, H 4.05, N 9.29\%.

\section{1-(4-Ethoxyacridin-9-yl)-1H-pyrrole-2,5-dione (6d)}

Microwave irradiation at $120{ }^{\circ} \mathrm{C}$ for $6 \times 2$ min (at power level of $600 \mathrm{Watt}$ for $6 \times 2 \mathrm{~min}$ ). Solvent of crystallization methanol. Yield $90 \%$. Yellow solid, mp $222-224{ }^{\circ} \mathrm{C}$. IR $(\mathrm{KBr}) v_{\max }: 1664(\mathrm{C}=\mathrm{O}), 1630(\mathrm{C}=\mathrm{N}), 1577,1510(\mathrm{C}=\mathrm{C}$, Ar) $\mathrm{cm}^{-1} .{ }^{1} \mathrm{H}$ NMR $\left(500 \mathrm{MH} z\right.$, DMSO- $\left.d_{6}\right) \delta: 1.49-1.52(\mathrm{t}$, $\left.3 \mathrm{H}, J=7 \mathrm{~Hz}, \mathrm{CH}_{3}\right), 4.37-4.41(\mathrm{q}, 2 \mathrm{H}, J=7,14 \mathrm{~Hz}$, $\left.\mathrm{OCH}_{2}\right), 6.03(\mathrm{~s}, 2 \mathrm{H}, \mathrm{CH}=\mathrm{CH}), 7.48-8.59(\mathrm{~m}, 7 \mathrm{H}, \mathrm{Ar}-\mathrm{H})$. ${ }^{13} \mathrm{C}$ NMR $\left(125 \mathrm{MHz}\right.$, DMSO- $\left.d_{6}\right) \delta: 14.59,65.36,111.81$, $112.35,113.96,115.06,120.20,122.60,124.36,124.66$, $131.63,135.51,136.40,139.53,147.85,157.38,168.33$, GC-MS: $m / z, 318\left(\mathrm{M}^{+}, 5 \%\right), 273\left(\mathrm{M}^{+}-\mathrm{OC}_{2} \mathrm{H}_{5} ; 10 \%\right), 222$<smiles>COc1cccc2cc3ccccc3nc12</smiles> 
Calcd for $\mathrm{C}_{19} \mathrm{H}_{14} \mathrm{~N}_{2} \mathrm{O}_{3}$ : C 71.69, H 4.40, N 8.80; Found C 71.76, H 4.53, N $8.95 \%$.

\section{Pharmacology}

In vitro anticancer activity against human cancer cell lines (Mosmann 1983)

Human breast (T47D), lung (NCI-H522), colon (HCT-15), ovary (PA-1), and liver (HepG2) cancer cell lines were obtained from the National Center for Cell Science (NCCS), Pune, India. Cells were grown in tissue culture flask in complete growth medium (RPMI-1640 medium with $2 \mathrm{mM}$ glutamine, $\mathrm{pH} 7.4$ supplemented with $10 \%$ fetal bovine serum, $100 \mu \mathrm{g} / \mathrm{ml}$ streptomycin, and 100 units/ $\mathrm{ml}$ penicillin) in a carbon dioxide incubator $\left(37^{\circ} \mathrm{C}, 5 \%\right.$ $\left.\mathrm{CO}_{2}, 90 \% \mathrm{RH}\right)$. All cell culture reagents were from GIBCO (Invitrogen, USA). Penicillin, streptomycin, MTT (3-(4,5-dimethyl-2-thiazolyl) 2,5diphenyl- $2 \mathrm{H}$ tetrazoliumbromide), cell culture grade DMSO, 5 fluorouracil (5-FU), cyclophosphamide, and actidione (cycloheximide) were from Himedia (Mumbai, India).

MTT assay was carried out as described in the literature (Mosmann 1983). In brief, $5 \times 10^{3}$ cells in $200 \mu \mathrm{l}$ of medium were seeded in 96-well plates (Griener, Germany). Serial dilutions of compound initially ranging from 0 to $100 \mu \mathrm{M}$ in DMSO were added to the monolayer. The final DMSO concentration for all dilutions was $0.1 \%$ which was used as vehicle control. The cultures were assayed after $24 \mathrm{~h}$ by the addition of $50 \mu \mathrm{l}$ of $5 \mathrm{mg} / \mathrm{ml}$ MTT and incubating for another $4 \mathrm{~h}$ at $37^{\circ} \mathrm{C}$. The MTT-containing medium was aspirated and $200 \mu 1$ of DMSO (Himedia, Mumbai, India) and $25 \mu \mathrm{l}$ of Sorensen glycine buffer $(0.1 \mathrm{M}$ glycine and $0.1 \mathrm{M} \mathrm{NaCl}, \mathrm{pH} 10.5$ ) were added to lyse the cells and solubilize the water insoluble formazone. Absorbance of the lysates was determined on a Fluostar optima (BMG Labtech, Germany) microplate reader at $570 \mathrm{~nm}$.

The percentage inhibition was calculated as follows: facility. Ms. Surbhi Arya (SRF) to CSIR New Delhi and Mr. Anuj Kumar to MHRD, New Delhi are thankful for financial assistance.

\section{References}

Albert A, Gledhill W (1945) Improved syntheses of aminoacridines. IV. Substituted 9-aminoacridines. J Soc Chem Ind-L 64:169-172

Albert A, Ritchie B (1960) 9-Aminoacridine. Org Synthesis Coll 3:53-56

Ali TE-S, El-Kazak AM (2010) Synthesis and antimicrobial activity of some new 1,3-thiazoles, 1,3,4-thiadiazoles, 1,2,4-triazoles and 1,3-thiazines incorporating acridine and1,2,3,4-tetrahydroacridine moieties. Eur J Chem 1:6-11

Allen CFH, Mckee GHW (1959) Acridone. Org Synthesis Coll 2:15-17

Aly EI, Abadi AH (2004) Synthesis and antitubercular activity of 6-chloro (unsubstituted)-2-methoxy-9-substituted acridine derivatives. Arch Pharm Res 27:713-719

Aly ME-M, Ebeid MY, Aly EI, Seri SMA (1997) Potential anti-HIV agents: synthesis and anti-HIV-1 activity of some $N$-substituted 9-(4sulfamoylphenylamino)-2-acridinyl-, 9-oxo-9,10-dihydro-2-acridinyl- and 9-amino-2-acridinyl-[ $N$-(4-sulfamoylphenyl)] carboxamide derivatives. Bull Fac Pharm (Cairo University) 35:185-197

Chen Y-L, Lu C-M, Chen I-L, Tsao L-T, Wang J-P (2002) Synthesis and antiinflammatory evaluation of 9-anilinoacridine and 9-phenoxyacridine derivatives. J Med Chem 45:4689-4694

Di Giorgio C, De Meo M, Chiron J, Delmas F, Nikoyan A, Jean S, Dumenil G, Timon-David P, Galy J-P (2005) Synthesis and antileishmanial activities of 4,5-di-substituted acridines as compared to their 4-mono-substituted homologues. Bioorg Med Chem 13:5560-5568

El-Deiry WS (2008) Acridine compound activation of p53 and use for the treatment of cancer. WO 2008010984 A2 20080124

Goodell JR, Madhok AA, Hiasa H, Ferguson DM (2006) Synthesis and evaluation of acridine- and acridone-based anti-herpes agents with topoisomerase activity. Bioorg Med Chem 14:5467-5480

Gopalan B, Gharat LA, Khairatkar-Joshi N (2006) Preparation of acridine, phenazine and oxanthrene-1-carboxamides as PDE4 inhibitors for treatment of asthma and chronic pulmonary disease. WO 2006040650 A1 20060420

Gupta HC, Jaiswal V (2010) Synthesis and antiviral activity of some acridin-9-yl aryldithiocarbamates. Indian J Heterocycl Chem 19:409-410

Kumar A, Srivastava K, Kumar SR, Puri SK, Chauhan MS (2009) Synthesis of 9-anilinoacridine triazines as new class of hybrid antimalarial agents. Bioorg Med Chem Lett 19:6996-6999

Mean OD of vehicle treated cells (negative control) - Mean OD of treated cells $\times 100$

Mean OD of vehicle treated cells (negative control)

The $\mathrm{IC}_{50}$ values were calculated using graph pad prism, version 5.02 software (Graph Pad Software Inc., CA, USA).

Acknowledgments We are thankful to technical staff of the Chemistry Department, I. I. T. Roorkee, for spectroscopic studies and elemental analysis. Thanks also due to Head I.I.C. for providing NMR
Lp NY, Lp FCF, Hu Y, Han Y, Chung SK (2008) Preparation of acridine derivatives as cholinesterase inhibitors. WO 2008091901 A1 20080731

Maurice HB, Phillips R, Karodia N (2009) Design, synthesis and biological evaluation of novel acridine-polyamine conjugates against prostate cancer. Afr J Pharm Pharacol 3:602-610

Mosmann T (1983) Rapid colorimetric assay for cellular growth and survival: application to proliferation and cytotoxicity assays. J Immunol Methods 65:55-63 
Prabakaran K, Yamuna E, Prasad KJR (2011) Synthesis and antimicrobial activities of nitro substituted indolo[3,2-c]acridines. Indian J Chem, Sect B 50B:906-909

Sondhi SM, Singh J, Rani R, Gupta PP, Agarwal SK, Saxena AK (2010) Synthesis, anti-inflammatory and anticancer activity evaluation of some novel acridine derivatives. Eur J Med Chem 45:555-563

Sondhi SM, Kumar S, Rani R, Chakraborty A, Roy P (2013) Synthesis of bis acridine derivatives exhibiting anticancer and anti-inflammatory activity. J Heterocycl Chem 50:252-260

Srivastava A, Nizamuddin (2004) Synthesis and fungicidal activity of some acridine derivatives. Indian $J$ Heterocycl Chem 13:261-264

Tomer V, Bhattacharjee G, Kamaluddin, Rajakumar S, Srivastava K, Puri SK (2010) Synthesis of new chalcone derivatives containing acridinyl moiety with potential antimalarial activity. Eur J Med Chem 45:745-751

Tonelli M, Vettoretti G, Tasso B, Novelli F, Boido V, Sparatore F, Busonera B, Ouhtit A, Farci P, Blois S, Giliberti G, La Colla P
(2011) Acridine derivatives as anti-BVDV agents. Antiviral Res 91:133-141

Tripathi RP, Verma SS, Pandey J, Agarwal KC, Chaturvedi V, Manju YK, Srivastva AK, Gaikwad A, Sinha S (2006) Search of antitubercular activities in tetrahydroacridines: synthesis and biological evaluation. Bioorg Med Chem Lett 16:5144-5147

Vogel AI (1968) A textbook of practical organic chemistry, ELBS London Wurster S, Engstroem M, Savola J-M, Hoeglund I, Sallinen J, Haapalinna A, Tauber A, Hoffren A-M, Salo H (2001) Preparation of 4-(phenylamino)quinolines and 9-(phenylamino)acridines as $\alpha 2$-adrenoceptor antagonists. WO 2001064645 A2 20010907

Yartseva LV, Isayev SG, Svechnikova OM (2003) Synthesis, physicochemical properties, and biological activity of 9-acetylamino and arylamino derivatives of 5-nitroacridine. Farmatsevtichnii Zhurnal 3:60-64

Yu X-M, Ramiandrasoa F, Guetzoyan L, Pradines B, Quintino E, Gadelle D, Forterre P, Cresteil T, Mahy J-P, Pethe S (2012) Synthesis and biological evaluation of acridine derivatives as antimalarial agents. Chem Med Chem 7:587-605 